\title{
Conceptualising fun in mobile commerce environments
}

\section{Robert Davis}

\begin{abstract}
Consumers use mobile commerce services to hedonically experience 'fun'. This research explores what consumer-oriented service strategies have been adopted to enhance the fun experience. This research is a case study using grounded theory to develop the conceptual model, represented by 15 propositions, suggesting that attention be focused in three areas; content, social and self orientations. The first, relates to the way in which the service is constructed or the service content orientation. Secondly, the personal nature of the medium focuses attention on the consumer's social orientation. Finally, the consumers’ self orientation. Managerial and research implications are discussed.
\end{abstract}

Keywords: fun; hedonic; mobile commerce; conceptual; case study; mobile communication.

\section{Introduction}

The purpose of this research is to explore the consumer's experience of fun in mobile commerce (mcommerce) service environments (Laukkanen and Lauronen, 2005; Park, 2006). This is because such services have rapidly become an important aspect of consumers' daily consumption behaviour (Pantzar, 2003; Davis and Sajtos, 2008). Many researchers, such as Kumar (2004), have projected exponential growth in mobile phone users (Barnes, 2002b) and the m-commerce market (Siau et al., 2001; Ghosh and Swaminatha, 2001; Ingram, 2001; Sliwa, 2001; Siemens Mobile Marketing Intelligence Department, 2002; Barnes, 2002a). While this growth has been attributed to the utilitarian versatility of such services and technological advancements that give consumers the ability to conduct complex transactions ubiquitously, little attention has been given to other factors, such as those that are related to the consumer's hedonistic desire to use m-commerce services (AlShaali and Varshney, 2005) and experience fun intrinsically. For example, customers who routinely engage in mobile banking (Zarifopoulos and Economides, 2009) may also be interactive with the banking brand by using their mobile messaging service to respond to a campaign. In essence, while engaging in telic-serious goal-directed behaviours (e.g., checking an account balance) they can also experience the paratelic-fun of the brand. Experiencing fun is important for consumers as it creates a state of enjoyment that can be described as the subjective feeling that is the physiological response to the cognitive evaluation of the service experience (Stratton and Hayes, 1999, p.90).

Some researchers have begun to explore the consumers' hedonistic desire to experience the fun associated with using m-commerce services and its implications for existing practice (Agarwal and Karahanna, 2000; Barwise and Strong, 2002). They conclude that consumers' need to experience fun to alleviate the boredom associated with repetitive tasks, to enhance entertainment needs (Pantzar, 2003) and support peer-to-peer communications, interactivity or personalisation (Barnes and Scornavacca, 2004). Corporations such as Xbox and 20th Century Fox have begun to couple m-commerce services with other channels of communication (e.g., television), allowing consumers to interact with campaigns using text messaging (Barnes, 2002b; Ratsimor et al., 2003; Davis and Sajtos, 2008; Xu et al., 2009). This means consumers can now experience the fun of the advertised brand (de Kerckhove, 2002). Researchers also concluded that the experience of fun can enhance the effectiveness of a campaign, promote word-of-mouth in peer-to-peer interactions (Jones, 2002) and make consumers more receptive to receive permission-based marketing communications (Sheehan and Hoy, 1999; Haig, 2002; Barwise and Strong, 2002; de Kerckhove, 2002).

Despite the potential, practitioners and researchers have been slow to bridge the gap and adapt existing marketing strategies to the ones that target the consumers' hedonistic desire to experience fun for three reasons (Arnold and Reynolds, 2003). First, in general, there is a lack of research into m-commerce as a service (Balasubramanian et al., 2002; Watson et al., 2002; Andersson and Nilsson, 2000). In addition, 'fun' has not been a central concept of inquiry when researching consumers' use of technology dependant environments. The literature since the 1980s has viewed the consumers' behaviour as being a utilitarian rational decision-maker (Babin et al., 1994; Addis and Holbrook, 2001). The transactional perspective is typically symptomatic of this utilitarian approach (Coviello et al., 2002). However, the traditional utilitarian perspective has been slowly challenged by the emergence of alternative philosophies that focus on the consumers' behavioural and experiential drive for the need to have fun and pleasure (Holbrook and Hirschman, 1982; Arnold and Reynolds, 2003). This stream of enquiry has become more important for marketers because of the growth in technology that increasingly permeates consumers' lives (Agarwal and Karahanna, 2000; Addis and Holbrook, 2001). The focus has shifted towards the subjective needs of consumers in the consumption process and the symbolic importance in their lives. For example, Babin et al. (1994) identified the important role that hedonistic desire plays in the retail shopping process, while 
Holbrook and Hirschman (1982) highlighted the importance of culture and personality in the consumption experience (Kleijnen et al., 2004).

Second, existing studies in m-commerce service marketing are diverse and filled with competing perspectives (Nysveen et al., 2005). Until recently, these approaches have traditionally been dominated by the technological perspective (Barnett et al., 2000; Clarke III, 2001; Paavilainen, 2001; Siau et al., 2001; Barnes, 2002a; Haig, 2002). However, recent literature has challenged this approach by exploring consumer behavioural preferences for specific m-commerce services and the consumers' adaptation process encountered by m-commerce consumers (Anckar and D’Incau, 2002; Carroll et al., 2002; Magura, 2003). Researchers have also explored $\mathrm{m}$-commerce from the economic transactional exchange perspective (Tarasewich et al., 2002), and examined the various value chain alternatives needed for growing a capable and responsive m-commerce industry (Barnes, 2002a; Barnett et al., 2000; Siau et al., 2001; Ratsimor et al., 2001). Furthermore, the disparity in the literature has also been exacerbated by divergent definitions of mcommerce (Balasubramanian et al., 2002).

Finally, many marketers are reluctant to cross the divide from mass market to the peer-to-peer communications strategies commonly deployed in the m-commerce medium. This is because consumers are very intolerant of mass marketing communications (Barwise and Strong, 2002; de Kerckhove, 2002; Kleijnen et al., 2004; Duri et al., 2001) that are not permission-based from the consumers to execute communications strategies (Barnett et al., 2000; Haig, 2000; Barnes, 2002a; Ratsimor et al., 2003; Coursaris et al., 2003), and tailored to user-specific messages (Duri et al., 2001; Watson et al., 2002).

\section{$2 \quad$ Research question}

The research model applied to overcome this gap in the understanding of what approaches enhance the consumers fun experience in the consumption of m-commerce services is a case study using grounded theory as the mode of analysis. Further discussion and justification of this interpretive approach is provided in the final section of the paper. Operationally, this model explores the perceptions of senior marketing executives in the m-commerce industry in Asia who, over the last four years, have been directly involved in the development and implementation of consumer-oriented marketing strategies (Leppaniemi and Karjaluoto, 2005). These strategies are designed to enhance the consumers' state of cognitive enjoyment, subjective feelings and physiological responses to m-commerce services (Stratton and Hayes, 1999, p.90).

The approach of this study is inspired by previous researchers (Buellingen and Woerter, 2004; Vargo and Lusch, 2004; Levy, 2005) who have developed conceptualisations with the "aim of clarifying our understanding and addressing gaps in research at an 'embryonic stage' (Stern et al., 2002, p.15). To effectively understand the role of the consumers' fun experience in the consumption of m-commerce services, three research questions emerge from the literature. They relate to three key factors that play an important role in the consumers' fun experience:

1. content

2. social orientation

3. self orientation

Fun is defined as that "facet of consumer behaviour that relates to the multi-sensory aspects of one's experience” with services, where "multi-sensory means the receipt of experience” (Addis and Holbrook, 2001, p.59). Fun is further described as hedonic consumption, that is, intrinsically motivated rather than 'extrinsically valued' (Addis and Holbrook, 2001, p.59). The direction of this research is worthwhile since

\footnotetext{
"consumer researchers have devoted little attention to the underlying determinants of fun and playful activities even though it appears that consumers spend many of their waking hours engaged in events that can be explained on no other grounds.” (Holbrook and Hirschman, 1982, p.138)
}

This argument is pertinent in the context of m-commerce service environments. To address this question, we start by investigating the role of content in consumer fun (Siau et al., 2001; Curran et al., 2003; Kozinets et al., 2004). As Parasuraman (2000) argues, in services environments consumers are increasingly frustrated when interacting with technology-based systems. This is a situation compounded by a lack of research in service encounters and the role of the service content (Bitner et al., 2000). Therefore, the first research question that directs our conceptual model development is:

RQ1 What is the role of service-related content in the consumer's experience of fun while encountering m-commerce services?

Second, as Balasubramanian et al. (2002) and others (including Arnold and Reynolds, 2003) state, one of the most important dimensions of the m-commerce service encounter is encapsulated in the communication 
process between humans, that is, their social orientation (Haytko and Baker, 2004; Hennig-Thurau et al., 2004). Therefore, the second research question is:

RQ2 What is the role of the social orientation of consumers in their experience of fun while encountering m-commerce services?

Third, in the wireless medium the consumers self orientation is a vital element of their hedonic experience of fun (Babin et al., 1994). Recent research defines attention to self as being gratification shopping where attention is placed upon the want to "treat myself to something special” (Arnold and Reynolds, 2003, p.93) Therefore,

RQ3 What is the role of the self orientation of consumers in their experience of fun while encountering m-commerce services?

This paper is organised as follows. It proceeds with a description of the research method and approach to the conceptual model development. This is followed by a discussion of the main findings, followed by the conceptual model in the form of research propositions. The paper concludes with managerial and research implications. The paper contributes to mobile communication research in two ways. First, it makes a theoretical contribution by conceptualising the emerging role of the m-commerce service environment in the consumers' hedonic experience of fun. The paper also contributes to consumer behaviour by paying attention to the "underlying determinants of fun", "a vital link in further development of the experiential view” (Holbrook and Hirschman, 1982, p.138). Second, exploring some of the vital links will contribute to practitioners, creating insights that will direct service development. In the $\mathrm{m}$-commerce context, there is little guidance given to practitioners regarding the role of fun and what service providers can do to enhance the consumer's state of cognitive enjoyment.

\section{$3 \quad$ Method}

The research method is a case study of organisations and their expert executives in the m-commerce industry, using grounded theory as the mode of analysis (Taylor et al., 1996; McMahon et al., 2005; Li and McQueen, 2008). From an operational perspective, the case study method was based on a series of one-toone in-depth interviews with 29 participants in senior management positions (marketing management to vice president) within various firms in the mobile commerce industry in Thailand. It was designed "to obtain rich and detailed information” (Riege, 2003, p.75). All executives were fluent in English, with five hailing from Europe, 23 from Thailand and one from the USA. All interviews were conducted in English. The age range of participants was approximately 25-50 years, with most in the 30-40 years age bracket. The executive interviews were conducted in 2003 with follow-up discussions with some participants in 2004. All the interviews were conducted at the premises of the participant's work place. Thailand was chosen for the case study because of the maturity of the m-commerce market (Siemens Mobile Marketing Intelligence Department, 2002) where it is estimated that over $55 \%$ of all revenue comes from mobile data rather than traditional voice based services. Signed confidentiality agreements for each organisation and consent forms for each case participant were produced for ethical reasons. The time span of each interview varied between $30 \mathrm{~min}$ to $90 \mathrm{~min}$. The 29 participants represented four distinct activities in the industry. Eight interviewees represented 'mobile device manufacturers', two represented 'network providers', 13 represented 'content aggregators', and six represented 'content providers'. Overall, the companies involved in the study embodied a significant proportion of the overall market size in terms of market share (Siemens Mobile Marketing Intelligence Department, 2002). The participant companies are as follows, showing the executive participants' codes with all personal identities removed for reasons of confidentiality (Table 1). 


\begin{tabular}{|c|c|}
\hline Code & Position \\
\hline \multicolumn{2}{|c|}{ Mobile Device Manufacturer: Participant Company: Siemens Mobile (www.siemens.com) } \\
\hline OC_1 & Marketing Consultant \\
\hline OC_2 & Technical Marketing Executive \\
\hline OC_3 & Marketing Intelligence Manager \\
\hline OC_4 & President \\
\hline OC_5 & Marketing Vice President \\
\hline OC_6 & Technical Marketing Executive \\
\hline OC_ 7 & Sales Vice President \\
\hline OC_ 8 & Technology Vice President \\
\hline \multicolumn{2}{|c|}{ Network Provider: AIS (www.ais.com.th) and DTAC (www.dtac.co.th) } \\
\hline $\mathrm{OC} 9 \mathrm{~N}$ & Director - Product Development Executive \\
\hline OC_10N & Director - Product Management \\
\hline \multicolumn{2}{|c|}{$\begin{array}{l}\text { Content Aggregators: Shinee.com (www.shinee.com), Siam2U.com (www.siam2u.com), } \\
\text { MovieSeer.com (www.movieseer.com), M-Web (www.mweb.com) }\end{array}$} \\
\hline OC_11C & CEO \\
\hline OC_12C & Senior Programmer \\
\hline OC_ $13 \mathrm{C}$ & Graphic Designer \\
\hline OC_14C & Marketing Manager \\
\hline OC_15C & Vice President \\
\hline OC_16C & Project Manager \\
\hline OC_17C & Marketing Executive \\
\hline OC_18C & Product Development Executive \\
\hline OC_19C & Content Management Executive \\
\hline OC_20C & Business Development Executive \\
\hline OC_21C & CEO \\
\hline OC_22C & Technical Director \\
\hline OC_23C & Commercial Project Director \\
\hline \multicolumn{2}{|c|}{ Content Providers: RS Promotions (www.rs.co.th), Beci-TV3 (www.becworld.com) } \\
\hline OC_24P & Business Development Director \\
\hline OC_25P & Assistant Development Manager \\
\hline OC_26P & Managing Director \\
\hline OC_27P & General Manager - Marketing \\
\hline OC_28P & Technology Director \\
\hline OC_29P & Product Marketing Manager \\
\hline
\end{tabular}

The validity and reliability of the case study was tested by controlling the two characteristic risks that are associated with the case study design (Yin, 1994). The first area of concern with case study research relates to the interviewer's readiness and training, as well as the ideological position of the interviewer. To minimise interviewer bias, a single experienced interviewer was used to ensure consistency of data collection. To maintain the integrity of data analysis for parsimonious theory building (Eisenhardt, 1989), two researchers were used to analyse the evidence. The primary researcher conducted coding protocols in accordance with the research questions, whilst the second researcher ensured that the analysis was parsimonious with the research design. The results of the analysis were provided to all research participants in the form of a workshop. This gave an opportunity for further verification and development of the findings. The 29 interview transcripts generated 4495 individual text units. These were subsequently filtered and reduced to 2011 text units. A content analysis method was used to analyse the text units against the three research questions in accordance with the procedures outlined by Miles and Huberman (1994). Five percent of filtered text units were omitted from the analysis because of: 

a. incoherent statements
b. repetition of text units
c. interviewee's paraphrasing the interviewer's question
d. the interviewee's lack of comprehension of the question

\section{$4 \quad$ Results}

\subsection{RQ1: Service content orientation (P1 to P5)}

The executives thought that revenue generation was initially derived from the consumers' adoption of traditional transactional services (e.g., mobile banking), but they learned that it was in fact the consumers' greater desire to derive fun from the services that were novel and/or challenging. This view was strongly argued by a content aggregator marketing executive. It was discovered that the mobile device and related services are seen more as a toy to play games rather than a tool to support rational behaviours. This view may reject the utilitarian view that the service content should be developed with reference to some functional context:

\section{Content Generates Revenue:}

“Horoscopes are popular because they're fun. But things that are not fun are not making money.” [OC_17] Marketing Executive

\section{Content Generates Fun:}

"People are not transacting, I think people are using it for fun or they're using it for information ... but people will not do any mobile transaction or kind of commerce over the handset. Banks tried to launch it but it failed.” [OC_17] - Marketing Executive

\section{Novel Content:}

"I think because it's fun for them ... like people want to have fun ... to see the picture or graphics of someone they know ... or something funny on their mobile phone ... but I think it's quite popular here in Thailand. And now we move the business and start doing it too ... Something like Christmas and New Year ... snowflake or Halloween ... that kind of stuff's quite popular ... ." [OC_11] - CEO

Two senior executives argued that to maximise the experience of fun, service development might apply a game-structure, thus creating content that entices the consumer to be challenged and have fun:

\section{Game Content:}

“They don’t like to read like serious content or much writing. They would like to try the new games. They would like to try it out, see how it works and what they can win.” [OC_21] - CEO

\section{Challenging:}

"I think they like to be relating to fun. They ... have just their world ... and they enjoy their world ... I think some kind of interaction and really you know, challenge ... that would be more .... that is the fun that they would like ... want to have more.” [OC_6] - Technical Marketing Executive

As a toy, when the consumers perceived the service as new and fun, it elevated the consumers' enticement and engagement towards that service. The objective was to see the service eventually become an integrated part of the consumers' everyday life pursuit of the fun experience. The consumers' adoption and integration of a service would be governed by the perception of the mobile service as a provider of new and fun experiences. This argument was supported by a content aggregator executive:

Newness:

"Because it's a new thing for them. They like the new things that can make them fun .... ." [OC_19] Content Management Executive 
Toy:

"It's like when you've got a new toy; you are very excited, you are very eager to play with them.” [OC_19] Content Management Executive

Integration and adaptation are normally slowed by the technology itself, as was observed by a network operator product management director. The wide array of competing and different service platforms, models and handset brands means that consumers are bound to experience some degree of incompatibility:

Compatibility:

“Sometimes I can download but I can’t send it to my friend ...” [OC_10] - Director - Product Development

Convenience and Adaption:

"I just feel that the mobile phone seems to be the next necessary thing for the consumer. So anything that is possible for them to use with the mobile phone makes their life more fun [and] easier.” [OC_22] - Technical Director

Developing an adaptation process that engages the consumers in playful fun reduces the incompatibility issues of integrating the service into the consumers' behavioural patterns. Hence, when the consumers achieve a level of integration, they are able to adapt or personalise their use of technology and associated services to specific experiential needs, such as the need for peer-to-peer interactivity. The need to develop interactive technologies was seen by one senior programmer (content provision):

\section{Entertainment and Personalisation:}

"The reason for this I believe is because of the entertainment twist or the personalisation twist, as you can personalise your mobile phone.” [OC_20] - Business Development Executive

Interactivity:

“It’s a very interactive consumer experience.” [OC_12] - Senior Programmer

\subsection{RQ2: Social orientation (P6 to P13)}

Mobile devices also serve the growing social function of acting as an intermediary for social interaction with peers. In other words, they can create more time for the pursuit of hedonistic pleasures. In this context some consumers will actually purchase common sayings in the form of content that are sent to other consumers for the purpose of creating and engaging others in the experience of fun:

Mobile is an Intermediary:

"I mean I often say I have messages which are pre-defined, you know as in a template, like "let's go out for dinner" or "let's go have a drink", you know stuff like that, that I could just whip off and send them whenever I want .... ." [OC_12] - Senior Programmer

In the mobile environment, generating fun through m-commerce applications does not impact on the technological elements of the medium; instead, it has an effect on the social (to express and influence peers) processes which businesses view as increasing the consumers' interactivity with the content:

Versatility:

"You can go out and snap a photo of your friend; you can send it to your other friends." [OC_12] - Senior Programmer

However, as argued by one network operator product management director, the type and the nature of the fun generated through mobile communications is inherently determined by the channel characteristics, such as SMS, and MMS. Moreover, it is argued that the unique characteristics influence and strengthen the peerto-peer relationship in different ways.

\section{Shared Group Experience:}

"Sometimes I can download but I can't send it to my friend or girlfriend because ... their mobiles do not support MMS.” [OC_10] - Director - Product Development 
Fun is a key element of relationship building among the consumers' peers. The line between individualism and altruism is intertwined as the use of humour reinforces both the self-worth of the user and the interdependent collective bonds between the group members. For example, text or picture messaging services facilitate the connections openly or discreetly within social collectives, or differentiate between collective structures (work vs. friends). Not surprisingly, two business development executives involved with content development and aggregation argued for the need for services with a strong social and collective orientation:

\title{
Social Activity:
}

"They send straight out to up to 10 of their friends ... for example like "hey this movie is fun ... do you want to join us for the evening?” [OC_9] - Director - Product Development

\section{Collective Orientation:}

\begin{abstract}
"I think it's more social and it's more fun having more people together. Rather than just two." "I think that we're in a group because we think we have something in common ... a common perspective of life, that brings us together, and we share. So we go out together, we share memories, and have fun together. We have the same family background, so we talk the same language. So the group is not like anyone can be any group.”[OC_24] - Business Development Director
\end{abstract}

Fun was used in the different m-commerce communication channels as a form of individual expression of feelings. It was also used to influence and impress collective peers in ways which were less direct or would otherwise have been socially inappropriate. Senior executives cited the need to develop service applications to take account of the inherent personal nature of the mobile device:

\section{Channel of Expression:}

“For some occasions ... you may use SMS rather than making a call.” [OC_7] - Sales Vice President

\section{Self Expression:}

"Mobile Communications is about self expression towards the societal members but that's actually taking something which is essentially purely fun, and actually giving it some pertinence. Because if I'm not looking at my phone I know who's ringing or I know, you know, I maybe differentiating a work call from a personal call, or something to do with that. It is actually developing a purpose for something which is actually sort of more fun, albeit in a light-minded way. And it may, people may use that ... either consciously or otherwise to sort of, indicate how they feel about somebody.” [OC_25] - Assistant Development Manager

Beyond the experience of expressing oneself through m-commerce services, participants used fun to acculturate each other into specific social system consumption behaviours. The specific nature of these consumption patterns was directed towards brand and content preferences, resulting in increasing interdependency on the social relationship:

\section{Consumption Behaviour and Social Experience:}

"They will follow their friends. Like if their friends have a Nokia ..." "Many young people in Thailand love to download ... They want to show their friends that hey, they have the new logos, they have the new pictures, (and) they have the new ring tones. It’s for fun ...” [OC_9] - Director - Product Development

\subsection{RQ3: Self orientation (P14 to P16)}

The study identified hedonism rather than rationalism as the key motivator for consumers to use the services in the m-commerce medium. It was argued by content aggregation executives that services that were shown to offer the consumers fun, entertainment and that appeared to be trendy had the greatest amount of attraction and continual use for the consumers.

\section{Entertainment:}

"I think they're more fun and entertaining and trendy. It's not something that we need to have but it'd probably be nice.” [OC_17] - Marketing Executive

This concept may also relate to the fact that the device symbolically indicates that they are part of a particular fashion:

\section{Trendiness:}

"Like a teenager, they love to use [the mobile phone] the most. I mean not the most... expensive one, because 
it makes them very in trend[y], and because it is the expensive one. They decided to purchase the new handset despite the fact that they don't even use it to its full capacity.” [OC_19] - Content Management Executive

Whilst fun was used as an attractor, services usage tended to be functionally driven by the hedonistic behaviour of escapism, or to avoid boredom. In contrast, alternative channels such as the internet were not perceived to be as enjoyable because of the lack of immediacy in the delivery of information:

\section{Relieves Boredom:}

"It seems to be that the SMS is filling some specific occasions or it’s used for a specific purpose.” [OC_7] Sales Vice President

\section{Hedonistic Choice:}

“... they would like to be entertained, more than searching through information. That's why basically they come to the website, they may read some articles, content.” [OC_21] - CEO

\section{Pacification:}

"I'd definitely think that the western consumer is thinking well how can it better serve me, save me money, or along those lines. Or unless it's like really cool, you know they could show their friends or something like that. But I don't think they're as much into the fun aspect unless it's maybe a game. But, whereas Asia, you know it's something that is just fun. You know, it falls in that one definition of fun. It's like it's a short form of entertainment that pacifies them for a while.” [OC_12] - Senior Programmer

\section{$5 \quad$ Conceptual model}

The representation and discussion of the emerging conceptual model of the emerging role of fun in the consumers consumption experience of m-commerce services is presented in a series of research-based propositions.

\subsection{Service content orientation}

It is concluded that to enhance the consumers sense of fun, emphasis should be placed on the need to communicate, seek information (Park, 2006) and be entertained ubiquitously (P1 to P2) (Barnes and Scornavacca, 2004). Attention should also be given to the physical context of the consumer. While the consumers maybe ubiquitous, their physical context may determine or dictate whether they wish to pursue hedonic or utilitarian experiences. Therefore it is proposed that:

P1 The consumer's consumption experience of fun arises from obtaining content through ubiquitous channels that are novel and/or challenging.

P2 The consumer's consumption experience of fun arises from entertainment related content needs rather than transactional potential.

From a service adaptation perspective, there is also the need to ensure that the product and the service development do not create incompatibility issues (P3-P5) (Andreou et al., 2005). This is because, in the consumers' continual search and desire for new fun experiences, they will be frequently refreshing their own technologies (software and hardware). Disruptions to this process will create a less than interactive experience (Koivumaki et al., 2006). Childers et al. (2001) support this view, arguing for the importance of interactivity in hedonic consumption. They also cite the importance of service navigation flexibility in consumers' perceptions of interactive media use. However, it is noted that web-based consumer research needs to be carefully examined before it is generalised broadly into m-commerce services (Balasubramanian et al., 2002). Therefore, it is proposed that:

P3 The consumer's consumption experience of fun arises when content incompatibility is minimal.

P4 The consumer's consumption experience of fun arises when there is an attitude to adopt new content and technology.

P5 The consumer's consumption experience of fun arises when there is an interactive experience. 


\subsection{Social orientation}

An important aspect of the experience of fun for consumers in m-commerce environments is their interaction with other consumers (P6 to P13). This view is supported by Arnold and Reynolds (2003) in their 'social shopping' category of hedonic motivations. Their qualitative model argues that consumers see the social experience as the primary reason for shopping. In their findings, it was found that a sense of community, with possibly multiple known and unknown participants, can be created and maintained ubiquitously in the m-commerce environment (Barnes and Scornavacca, 2004). Simple interpersonal communication can create a playful experience when consumers start to express feelings and moods in different ways using different forms and ways of communication. It was also found that from a social orientation, the consumers' consumption experience of fun played an important role when there was a need to impress and challenge peers, possibly through the adoption of trends and fashions. This is supported by Haytko and Baker (2004) in their study of the hedonic experiences of adolescent girls. It is suggested in these research findings that the role of peers and trends in the m-commerce space may relate to a wider demographic group, possibly up to the age of 25 years. The way of having fun with the process of communication with other consumers is important when consumers start to display and manipulate their own as well others' perceptions of their image and status. Consumers can also play with the process of communication, as the technologies allow them to decide which participants they communication with, as well as how. In the latter form, communications can also be made less intrusive. Therefore, it is proposed that:

P6 The consumers' consumption experience of fun arises from informal communication that is not hindered by their physical context.

P7 The consumers' consumption experience of fun arises when there is a desire for companionship and community.

P8 The consumers' consumption experience of fun arises when there is a need to impress and challenge peers.

P9 The consumers' consumption experience of fun arises from the adoption of trends and fashions.

P10 The consumers' consumption experience of fun arises when there is a need to reflect an individual's personality and status.

P11 The consumers' consumption experience of fun arises when there is a need to express feeling indirectly.

P12 The consumers' consumption experience of fun arises when differentiation of the sender can occur in peer to peer communication.

P13 The consumers' consumption experience of fun arises when communication is less intrusive and the recipient can receive and send messages discreetly.

\subsection{Self orientation}

For consumers to maximise their experience of fun using m-commerce services it is important that they become an integral part of their lifestyle, not only to reduce task repetition and productivity but also to help meet the needs of a perceived luxury lifestyle (P14 to P16). Like Childers et al. (2001) and Arnold and Reynolds (2003), self orientations are important components of hedonic motivations. The results suggest that consumers may also experience fun when they are pursing utilitarian goals such as convenience (Park, 2006). Therefore, it is proposed that:

P14 The consumers' consumption experience of fun arises when there is a need to enhance consumer experience by reducing repetitive tasks and increasing productivity.

P15 The consumers' consumption experience of fun arises when the m-commerce device becomes a necessity of lifestyle.

P16 The consumers' consumption experience of fun arises from the pleasure of meeting their hedonic needs. 


\section{$6 \quad$ Managerial implications}

In summary, the propositions indicate to researchers and practitioners that to enhance the consumer's hedonic consumption experience of fun, attention should be focused on three core areas. The first relates to the way in which the service itself is constructed, that is, technology and content. As many have argued, in services environments consumers are increasingly frustrated when interacting with technology-based systems (Kozinets et al., 2004; Curran et al., 2003; Siau et al., 2001; Parasuraman, 2000; Bitner et al., 2000). Second, due to the intensely personal nature of the m-commerce medium, the fun experience will be enhanced when the focus of the service encounter is on the communication process between humans, that is, their social orientation (Haytko and Baker, 2004; Hennig-Thurau et al., 2004; Arnold and Reynolds, 2003; Balasubramanian et al., 2002). The third core area is the consumers' self orientation (Arnold and Reynolds, 2003; Babin et al., 1994).

Research implications focus on understanding these findings in the context of practicing managers. In the realm of advanced technologies, the market must evolve but initially this development should be achieved by placing emphasis upon having fun. By doing this, it helps consumers achieve two things. First, it helps them to learn about new technologies which are not easy to use and time consuming to master (Figure 1). Just having fun is important to the learning process without them having the perception that if they make a mistake it can have significant implications. Second, having fun is also a key mechanism for building relationships, with the technology itself and with others (Figure 2.). Through building these relationships, other perceptions start to emerge concerning m-commerce. The most important of these is trust.

Figure 1 Market evolution

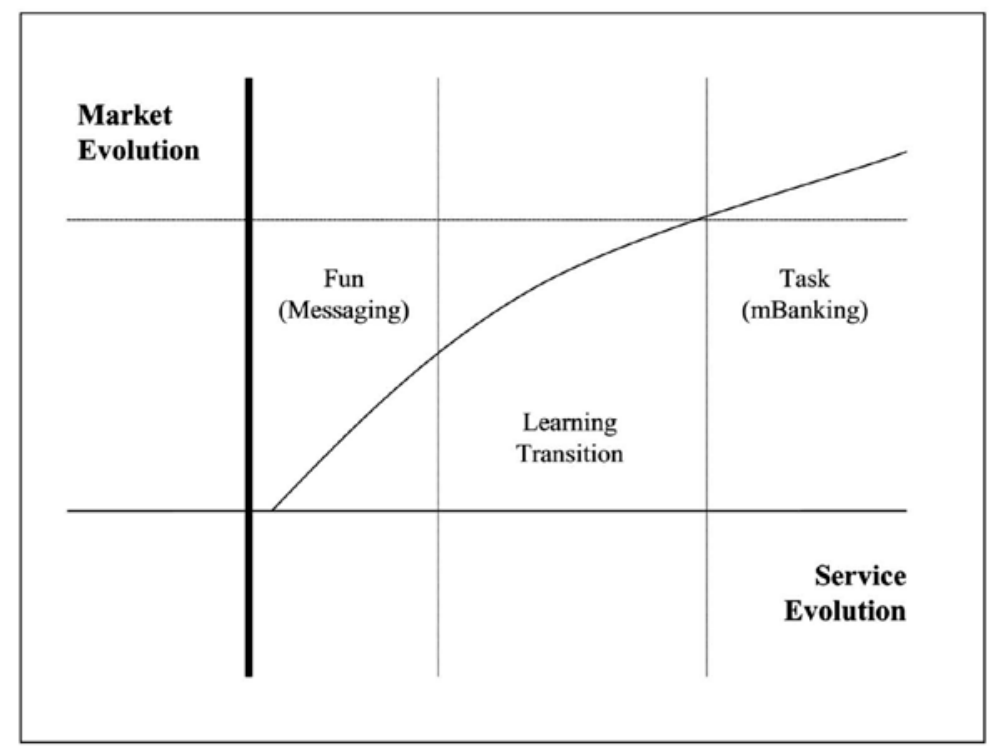


Figure 2 Building relationships

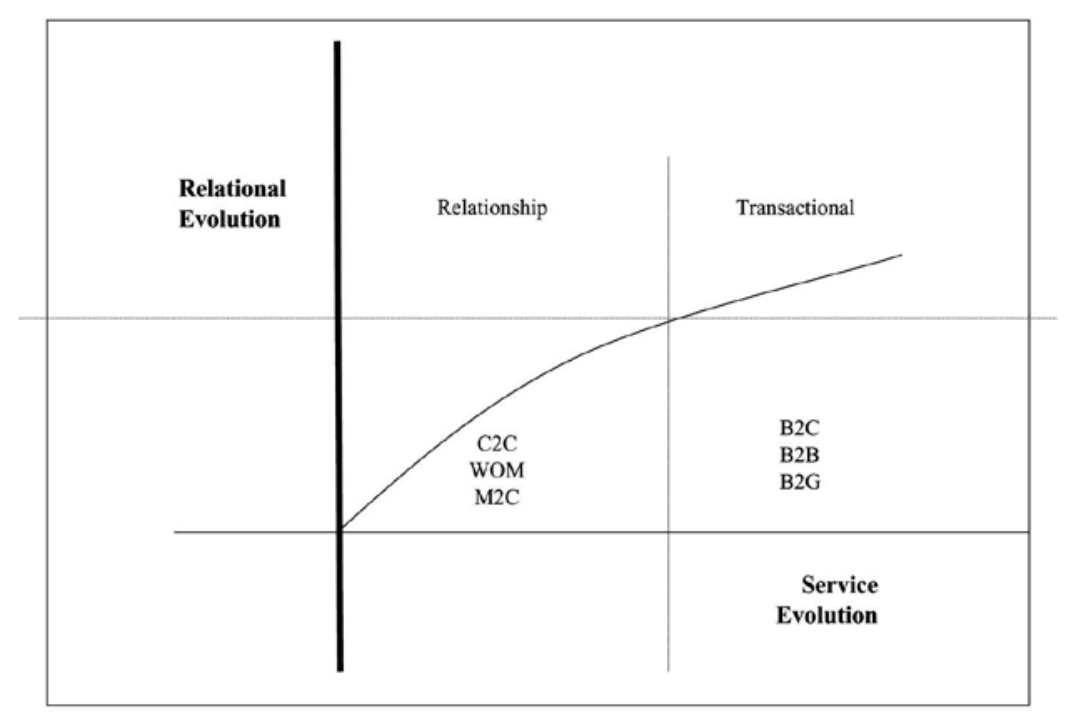

m-commerce service development and content should be dictated by the consumers' hedonic consumption, that is, intrinsically motivated (Holbrook et al., 1984) rather than 'extrinsically valued' (Addis and Holbrook, 2001, p.59). The content should be novel and challenging. The benefit to marketers, particularly in the early stages of service adoption, is that it aids the consumers' learning processes. Much of this learning will flow through their internal desire to personalise and adapt this content for their own convenience and lifestyle. Marketers may then find it easier to introduce m-commerce services and content that are more functional (e.g., mobile banking) and possibly more complex to a consumer market that has a higher level of knowledge about how to use the technology. Satisfying the consumers' hedonic desires will further be enhanced when emphasis is placed on reinforcing their self concept. A particularly important aspect of this will be their social orientation (Arnold and Reynolds, 2003). Fun is also the key to building relationships with other consumers by word of mouth.

\section{$7 \quad$ Limitations and directions}

It is possible that most of the criticism of this paper will arise from two aspects. The first will be because of the need to apply an alternative approach to answer the research questions. This differs from the traditional approach which begins with the development of a problem orientation, continues with the literature review, states the hypotheses and, finally, tests and discusses these through data collection and analysis. Hunt (1991) shows an extensive knowledge of this traditional approach to modern, positivist marketing theory development. However, in marketing research which challenges this dominant philosophy, significant debate rages concerning the appropriate method and philosophical approach that should be applied to generate scientific theory (Hunt, 1991). Characteristic of this debate is the position of who "attack positivism and positivistic social science that ... dominate contemporary marketing and social science.” The debate in marketing research and other disciplines extends to methodological issues which reflect the dichotomy of quantitative (positivistic) vs. qualitative (relativistic) approaches (Coviello, 1999). For example, Hunt (1991, p.398) seems to promote the former orientation but is led to conclude that "no single philosophy dominates marketing”, a conclusion supported by Orlikowski and Baroudi (1989) in their examination of 155 information systems research articles published from 1983 to 1988 . This debate highlights two key issues. The first relates to what good theory is and the implications for research method. The second demands that researchers clearly state their research philosophy and context so that individual readers can understand both the conceptual foundation and the direction of the research, thus gaining a deeper understanding of its external validity. This is particularly important where the goal of research is to explore rather than to generalise.

However, it is not the scope or desire of this research to become embroiled in what Orlikowski and Robey (1991) have defined as the persistent debate surrounding false and dangerous dichotomies (subjective vs. objective, socially constructed vs. material, macro vs. micro, and qualitative vs. quantitative). Instead, attention is given to the position and philosophy of the scientific approach that is applied in this research. This research can be best described as a case study of organisations and their expert executives in the mcommerce industry (Taylor et al., 1996). The advantages of applying this qualitative method is that "this type of empirical inquiry suits an investigation into a contemporary phenomenon from a real life context ... especially, when the boundaries between phenomenon and context are unclear” (Yin, 1994, pg. 13). 
Furthermore, the

“case study's realistic modes of inquiry lead to the discovery of new relationships or realities and build up an understanding of the meanings of experiences rather than verify predetermined hypotheses.” (Riege, 2003, p.77)

In essence, when no existing conceptual models exist, as in the context of our research questions, case study research promotes a process of sound theory development (Eisenhardt, 1989; Woodside and Wilson, 2003).

Support for this approach comes from research into information technology and systems literatures (Lee, 1991). As this research is inherently cross-disciplinary, that is marketing and IT, this is an important point. Also, similar methodological orientations have been applied in marketing where the objective is to develop a theory generalisable to a larger population, but where the mode of analysis, in response to a lack of literature based theory, has been grounded in empirical evidence. Lindberg-Repo and Grönroos’ (2004) recent paper on marketing relationships is characteristic of this approach. Others, for example, Manning et al. (1998) in the Journal of Retailing, used the grounded theory approach to examine the retailer's strategic response to manufacturers' everyday low cost programmes. Vlosky and Wilson (1997), in response to the lack of systematic research regarding channel relationships and specific detail on partnering relationships in business markets, used the case method guided by the grounded theory development approach. Rust (1993) also employed a similar mode of analysis to study the complex interactions between parents and children in shopping environments. One of the most important outcomes of this type of research is that it provides service marketing practitioners with some practical directions for service development in the wireless medium since the emerging theory is inspired by the practices of other managers with direct experiences of the phenomenon in question. As such, the method is

1. the most appropriate approach given the state of current knowledge

2. well supported in the marketing as well as information technologies literatures.

Second, some researchers will question the nature of the sample characteristics, that is, a Thai context. However, the sample was 20\% 'farang' (non-Thai) and most of the executives interviewed had extensive international business experience. Griffin et al. (2000), in their examination of the hedonic shopping values of Russian vs US consumers, found that "the similarity of hedonic shopping values across the two samples appears consistent” with existing theory (Griffin et al., 2000, p.48). In different research contexts and with reference to Thai consumers this view is challenged (Wong et al., 2003; Childers and Rao, 1992). We suggest future research programmes may clarify these issues. Future research may also focus on further qualitative work that models the role of m-commerce services in the consumers' social collectives. For example, researchers might measure word of mouth in these social networks or seek a cultural analysis using Hofstede's framework of analysis that seeks to measures the degree to which social networks reinforce individual or collective achievement and interpersonal relationships. Also, as other research has done, a cross-cultural perspective could be taken that seeks to provide some more objective evidence of the importance of hedonic values (Griffin et al., 2000).

\section{References}

Addis, M. and Holbrook, M.B. (2001) 'On the conceptual link between mass customization and experiential consumption: an explosion of subjectivity’, Journal of Consumer Behavior, Vol. 1, No. 1, pp.50-66.

Agarwal, R. and Karahanna, E. (2000) 'Time flies when you're having fun: cognitive absorption and beliefs about information technology usage’, MIS Quarterly, Vol. 24, No. 4, pp.665-694.

AlShaali, S. and Varshney, U. (2005) 'On the usability of mobile commerce', International Journal of Mobile Communications, Vol. 3, pp.29-37.

Anckar, B. and D’Incau, D. (2002) 'Value creation in mobile commerce: findings from a consumer survey', Journal of Information Technology Theory and Application, Vol. 4, No. 1, pp.43-64.

Andersson, A. and Nilsson, J. (2000) Wireless Advertising Effectiveness-Evaluation of an SMS Advertising Trial, Unpublished Marketing, Stockholm School of Economics, Sweden.

Andreou, A., Leonidou, C., Chrysostomou, C., Pitsillides, A., Samaras, G. and Schizas, C. (2005) 'Key issues for the design and development of mobile commerce services and applications', International Journal of Mobile Communications, Vol. 3, pp.303-323.

Arnold, M.J. and Reynolds, K.E. (2003) ‘Hedonic shopping motivations’, Journal of Retailing, Vol. 79, No. 2, pp.7795. 
Babin, B.J., Darden, W.R. and Griffin, M. (1994) 'Work and/or fun: measuring hedonic and utilitarian shopping value', Journal of Consumer Research, Vol. 20, No. 4, pp.644-656.

Balasubramanian, S., Peterson, R.A. and Jarvenpaa, S.L. (2002) 'Exploring the implications of m-commerce for markets and marketing', Journal of the Academy of Marketing Science, Vol. 30, No. 4, pp.348-361.

Barnes, S. and Scornavacca, E. (2004) 'Mobile marketing: The role of permission and acceptance', International Journal of Mobile Communications, Vol. 2, pp.128-139.

Barnes, S.J. (2002a) 'The mobile commerce value chain: analysis and future developments', The International Journal of Information Management, Vol. 22, pp.91-108.

Barnes, S.J. (2002b) ‘Wireless digital advertising: nature and implications’, International Journal of Advertising, Vol. 21, No. 3, pp.399-420.

Barnett, N., Hodges, S. and Wilshire, M.J. (2000) 'M-commerce: An operator's manual', The McKinsey Quarterly, Vol. 3, pp.162-173.

Barwise, P. and Strong, C. (2002) 'Permission-based mobile advertising', Journal of Interactive Marketing, Vol. 16, No. 1, pp.14-24.

Bitner, M.J., Brown, S.W. and Meuter, M.L. (2000) 'Technology infusion in service encounters', Journal of the Academy of Marketing Science, Vol. 28, No. 1, pp.138-149.

Buellingen, F. and Woerter, M. (2004) 'Development perspectives, firm strategies and applications in mobile commerce’, Journal of Business Research, Vol. 57, No. 12, pp.1402-1408.

Carroll, J., Howard, S., Peck, J. and Murphy, J. (2002) ‘A field study of perceptions and use of mobile telephones by 16 to 22 year olds', Journal of Information Technology Theory and Application, Vol. 4, No. 2, pp.49-61.

Childers, T.L. and Rao, A.R. (1992) 'The influence of familial and peer-based reference groups on consumer decisions', Journal of Consumer Research, Vol. 19, No. 2, pp.198-211.

Childers, T.L., Christopher, L.C., Peck, J. and Carson, S. (2001) 'Hedonic and utilitarian motivations for online retail shopping behavior’, Journal of Retailing, Vol. 77, No. 4, pp.511-535.

Clarke III, I. (2001) ‘Emerging value propositions for M-commerce’, Journal of Business Strategies, Vol. 18, No. 2, pp.133-149.

Coursaris, C., Hassanein, K. and Head, M. (2003) 'M-commerce in Canada: an interaction framework for wireless privacy’, Journal of Administrative Sciences, Vol. 20, No. 1, pp.54-74.

Coviello, N.E. (1999) 'Conducting cross-national research in relationship marketing: a discussion of methodological challenges’, Australasian Marketing Journal, Vol. 7, No. 1, pp.22-34.

Coviello, N.E., Brodie, R.J., Danaher, P.J. and Johnston, W.J. (2002) 'How firms relate to their markets: an empirical examination of contemporary marketing practices’, Journal of Marketing, Vol. 66, No. 3, pp.33-46.

Curran, J.M., Meuter, M.L. and Surprenant, C.F. (2003) 'Intentions to use self-service technologies: a confluence of multiple attitudes', Journal of Service Research, Vol. 5, No. 3, pp.209-224.

Davis, R.A. and Sajtos, L. (2008) ‘Conceptualizing and measuring consumer interactivity’, Journal of Advertising Research, Vol. 48, No. 3, pp.1-17.

de Kerckhove, A. (2002) 'Building brand dialogue with mobile marketing', Advertising and Marketing to Children, Vol. 3, July-September, pp.37-42.

Duri, S., Cole, A., Munson, J. and Christensen, J. (2001) 'An approach to providing a seamless end-user experience for location-aware applications', Paper presented at the Proceedings of the 1st International Workshop on Mobile Commerce, July, New York, pp.20-25.

Eisenhardt, K.M. (1989) ‘Building theories from case study research’, The Academy of Management Review, Vol. 14, No. 4, pp.532-552.

Ghosh, A.K. and Swaminatha, T.M. (2001) 'Software security and privacy risks in mobile e-commerce’, Communications of the ACM, Vol. 44, No. 2, pp.51-57.

Griffin, M., Babin, B.J. and Modianos, D. (2000) 'Shopping values of Russian consumers: the impact of habituation in a developing economy’, Journal of Retailing, Vol. 76, No. 1, pp.33-52.

Haig, M. (2002) Mobile Marketing: The Message Revolution, Kogan Page, London. 
Haytko, D.L. and Baker, J. (2004) 'It’s all at the mall: exploring adolescent girls' experiences’, Journal of Retailing, Vol. 80, No. 1, pp.67-83.

Hennig-Thurau, T., Gwinner, K.P., Walsh, G. and Gremler, D.D. (2004) 'Electronic word-of-mouth via consumeropinion platforms: What motivates consumers to articulate themselves on the Internet?', Journal of Interactive Marketing, Vol. 18, No. 1, pp.38-52.

Holbrook, M.B. and Hirschman, E.C. (1982) 'The experiential aspects of consumption: consumer fantasies, feelings, and fun', Journal of Consumer Research, Vol. 9, No. 2, pp.132-140.

Holbrook, M.B., Chestnut, R.W., Oliva, T.A. and Greenleaf, E.A. (1984) 'Play as a consumption experience: the roles of emotions, performance, and personality in the enjoyment of games', Journal of Consumer Research, Vol. 11, No. 2, pp.728-740.

Hunt, S.D. (1991) Modern Marketing Theory: Critical Issues in the Philosophy of Marketing Science, South-Western Pub. Co., Cincinnati.

Ingram, D. (2001) ‘The business case for a mobile economy’, Vital Speeches of the Day, Vol. 67, No. 20, pp.618-623.

Jones, A. (2002) 'Wireless marketing: the linking value of text messaging', Advertising and Marketing to Children, January-March, pp.39-44.

Kleijnen, M., de Ruyter, K. and Wetzels, M. (2004) 'Consumer adoption of wireless services: discovering the rules, while playing the game’, Journal of Interactive Marketing, Vol. 18, No. 2, pp.51-61.

Koivumaki, T., Ristola, A. and Kesti, M. (2006) 'Predicting consumer acceptance in mobile services: empirical evidence from an experimental end user environment', International Journal of Mobile Communications, Vol. 4, pp.418-435.

Kozinets, R.V., Sherry Jr., J.F., Storm, D., Duhachek, A., Nuttavuthisit, K. and Deberry-Spence, B. (2004) 'Ludic agency and retail spectacle', Journal of Consumer Research, Vol. 31, No. 3, pp.658-672.

Kumar, S. (2004) 'Mobile communications: global trends in the 21st century', International Journal of Mobile Communications, Vol. 2, No. 1, pp.67-86.

Laukkanen, T. and Lauronen, J. (2005) 'Consumer value creation in mobile banking services’, International Journal of Mobile Communications, Vol. 3, pp.325-338.

Lee, A.S. (1991) 'Integrating positivist and interpretive approaches to organizational research', Organization Science: A Journal of the Institute of Management Sciences, Vol. 2, No. 4, pp.352-365.

Leppaniemi, M. and Karjaluoto, H. (2005) 'Factors influencing consumers’ willingness to accept mobile advertising: a conceptual model’, International Journal of Mobile Communications, Vol. 3, pp.197-213.

Levy, S.J. (2005) 'The evolution of qualitative research in consumer behavior’, Journal of Business Research, Vol. 58, No. 3, pp.341-347.

Li, W. and McQueen, R. (2008) 'Barriers to mobile commerce adoption: an analysis framework for a country-level perspective’, International Journal of Mobile Communications, Vol. 6, pp.231-257.

Lindberg-Repo, K. and Grönroos, C. (2004) 'Conceptualizing communications strategy from a relational perspective', Industrial Marketing Management, Vol. 33, No. 3, p.229.

Magura, B. (2003) ‘What hooks m-commerce customers?’, MIT Sloan Management Review, Vol. 44, No. 3, p.9.

Manning, K.C., Bearden, W.O. and Rose, R.L. (1998) 'Development of a theory of retailer response to manufacturers’ everyday low cost programs’, Journal of Retailing, Vol. 74, No. 1, pp.107-137.

McMahon, R., DeVries, P. and Chong, P. (2005) ‘Building a wireless network infrastructure under budget constraints’, International Journal of Mobile Communications, Vol. 3, pp.445-456.

Miles, M.B. and Huberman, M.A. (1994) Qualitative Data Analysis: An Expanded Sourcebook, Sage, Thousand Oaks.

Nysveen, H., Pedersen, P.E., Thorbjørnsen, H. and Berthon, P. (2005) 'Mobilizing the brand: the effects of mobile services on brand relationships and main channel use', Journal of Service Research, Vol. 7, No. 3, pp.257-276.

Orlikowski, W. and Robey, D. (1991) 'Information technology and the structuring of organizations', Information Systems Research, Vol. 2, No. 2, pp.143-169.

Orlikowski, W.J. and Baroudi, J.J. (1989) ‘The information systems profession: myth or reality?’, Office: Technology and People, Vol. 4, No. 1, pp.13-30. 
Paavilainen, J. (2001) Mobile Business Strategies: Understanding the Technologies and Opportunities, Wireless Press, London.

Pantzar, M. (2003) 'Tools or toys - inventing the need for domestic appliances in postwar and postmodern Finland', Journal of Advertising, Vol. 32, No. 1, pp.83-93.

Parasuraman, A. (2000) 'Technology readiness index (TRI): A multiple-item scale to measure readiness to embrace new technologies', Journal of Service Research, Vol. 2, No. 4, pp.307-320.

Park, C. (2006) 'Hedonic and utilitarian values of mobile internet in Korea', International Journal of Mobile Communications, Vol. 4, pp.497-508.

Ratsimor, O., Korolev, V., Joshi, A. and Finin, T. (2001) 'Agents2Go: An infrastructure for location-dependent service discovery in the mobile electronic commerce environment', Paper presented at the Proceedings of the 1st international workshop on Mobile commerce, July, Rome, Italy, pp.31-37.

Ratsimor, O., Chakraborty, D., Joshi, A. and Finin, T. (2002) 'Discovery and advertising: allia: alliance-based service discovery for ad-hoc environments', Paper presented at the Proceedings of the 2nd International Workshop on Mobile Commerce, September, Atlanta, Georgia, USA, pp.1-9.

Ratsimor, O., Finin, T., Joshi, A. and Yesha, Y. (2003) 'eNcentive: a framework for intelligent marketing in mobile peer-to-peer environments', Paper presented at the Proceedings of the 5th International Conference on Electronic Commerce, September, Pittsburgh, Pennsylvania, pp.87-94.

Riege, A.M. (2003) 'Validity and reliability tests in case study research: A literature review with 'hands-on' applications for each research phase’, Qualitative Market Research: An International Journal, Vol. 6, No. 2, pp.75-86.

Rust, L. (1993) 'OBSERVATIONS: How to reach children in stores: marketing tactics grounded in observation research', Journal of Advertising Research, Vol. 33, No. 6, pp.67-72.

Sheehan, K.B. and Hoy, M.G. (1999) 'Flaming, complaining, abstaining: How online users respond to privacy concerns’, Journal of Advertising, Vol. 28, No. 3, pp.37-51.

Siau, K., Lim, E-P. and Shen, Z. (2001) 'Mobile commerce: promises, challenges, and research agenda', Journal of Database Management, Vol. 12, No. 3, pp.4-13.

Siemens Mobile Marketing Intelligence Department (2002) Overview of Mobile Marketing in Thailand. Siemens AG, Bangkok.

Sliwa, C. (2001) ‘China: The Web’s next frontier?’, Computerworld, Vol. 35, No. 22, 18 May, pp.1, 16.

Stern, B.B., Zinkhan, G.M. and Holbrook, M.B. (2002) 'The netvertising image: netvertising image communication model (NICM) and construct definition', Journal of Advertising, Vol. 31, No. 3, pp.15-27.

Stratton, P. and Hayes, N. (1999) A Student’s Dictionary of Psychology, 3rd ed., Arnold, London.

Tarasewich, P., Nickerson, R.C. and Warkentin, M. (2002) 'Issues in mobile e-commerce', Communications of the Association for Information Systems, Vol. 8, pp.41-64.

Taylor, R.E., Hoy, M.G. and Haley, E. (1996) ‘How French advertising professionals develop creative strategy’, The Journal of Advertising, Vol. 25, No. 1, pp.1-14.

Vargo, S.L. and Lusch, R.F. (2004) 'Evolving to a new dominant logic for marketing’, Journal of Marketing, Vol. 68, No. 1, pp.1-18.

Vlosky, R.P. and Wilson, E.J. (1997) 'Partnering and traditional relationships in business marketing: An introduction to the special issue', Journal of Business Research, Vol. 39, No. 1, pp.1-4.

Watson, R.T., Pitt, L.F., Berthon, P. and Zinkhan, G.M. (2002) 'U-commerce: Expanding the universe of marketing', Journal of the Academy of Marketing Science, Vol. 30, No. 4, pp.333-347.

Wong, N., Rindfleisch, A., Burroughs, J.E., Steenkamp, J-B.M. and Bearden, W.O. (2003) 'Do reverse-worded items confound measures in cross-cultural consumer research? The case of the material values scale', Journal of Consumer Research, Vol. 30, No. 1, pp.72-91.

Woodside, A.G. and Wilson, E.J. (2003) ‘Case study research methods for theory building', Journal of Business and Industrial Marketing, Vol. 18, Nos. 6-7, pp.493-508.

Xu, H., Oh, L. and Teo, H. (2009) 'Perceived effectiveness of text vs. multimedia location-based advertising messaging', International Journal of Mobile Communications, Vol. 7, No. 2, pp.154-177. 
Yin, R.K. (1994) Case Study Research: Design and Methods, 2nd ed., Vol. 5, Sage, Thousand Oaks.

Zarifopoulos, M. and Economides, A.A. (2009) 'Evaluating mobile banking portals', International Journal of Mobile Communications, Vol. 7, No. 1, pp.66-90. 